\title{
PURIFICATION PHASES OF ZINC SULPHATE SOLUTION OBTAINED FROM NEUTRAL LEACHING PROCESS OF ZINC CALCINE
}

\author{
${ }^{1}$ Nurten Deva, ${ }^{2}$ Musa Rizaj \\ 1,2University of Mitrovica, Department of Metallurgy and Materials, KOSOVA \\ ${ }^{1}$ nurtendeva@hotmail.com, ${ }^{2}$ mrizaj@hotmail.com
}

(Geliş/Received: 07.03.2018; Kabul/Accepted in Revised Form: 08.08.2018)

\begin{abstract}
The aim of this paper is based in analyze of the zinc sulphate solution obtained from neutral leaching process of zinc calcine in "Trepca" and its purification from impurities. This solution besides zinc contains also and other impurities such as $(\mathrm{Cu}, \mathrm{Cd}, \mathrm{Co}, \mathrm{Ni}, \mathrm{As}, \mathrm{Ge}, \mathrm{Sb}, \mathrm{Se}, \mathrm{Te}, \mathrm{Ag}$ etc.), which are with different concentrations. The sulphate solution can released from metal impurities based on the fact that they have higher electro - chemical potential than zinc and, as such, during the refining process they separate and precipitate in metallic form. Treatment of solution with appropriate technological methods technologically is very important in continuation of the electrolysis process and is accompanied by economic effects, because of non-ferrous and rare metals benefit. In this paper are described the phases of the purification process including acidic purification, cooling, needed materials and equipments for the refining process. Also, special attention is dedicated to the factors that have influence in the process development such as concentration, temperature, time, compressed air, etc.
\end{abstract}

Key Words: Zinc, Sulphate solution, Purification process, Impurities,

\section{INTRODUCTION}

The zinc industry is one of the most important nonferrous industries in world, based in the demand for zinc which is in increase stage, therefore this effects in rapid development of its industry, and his influence in economy in general is very obvious. Zinc sulfide ores are the main source of zinc metal in the world, however, some zinc is produced from oxide-carbonate ores and different secondary resources such as zinc ash, zinc dross, flue dusts of electric arc furnace, leach residues, etc. Most of the zinc smelting production processes, which includes roasting, leaching, purification and electrolysis, are hydrometallurgical. For the zinc electrolysis process, the purity of the used zinc sulphate solution is an imperative. In the roastleach process, very pure zinc sulphate solution must be prepared for zinc electrowinning, because the zinc ion is less noble than the hydrogen ion. The purity of electrolyte guarantees both obtaining highgrade cathode zinc deposit and reducing the amount of energy consumed for its procurement which considerably decreases the cost of zinc. The purity of the zinc sulphate solution, which is fed for electrolysis, is of great importance since the purity and structure of cathode zinc depend on it,as well as the coefficient of current utilization, the power consumption, the voltage of the tanks and other indices, which determine the zinc cost price (Boyanov et al., 2004). In the most common hydrometallurgical zinc process, $\mathrm{ZnO}$-rich calcine is first produced from sulphide or oxide-carbonate concentrates and then leached with hot sulphuric acid solution. After liquid/solid separation, the pregnant solution is purified and electrowon for metallic zinc production ( Turan et.al., 2004).

Therefore, the purification process is one of the most important unit processes in zinc hydrometallurgy. In hydrometallurgical zinc production, the purity of incoming solution subject to electrolysis is of great importance.

The aim of this paper is description of the phases of purification process of zinc sulphate solution gained from neutral leaching process in Trepca Company, including acidic purification and cooling along with specific equipment and materials. This paper as well described impurities which are contents 
of solution, and their negative effects in next process such is electrolysis process of zinc. Even a small amount of these metallic ions of impurities in the solution may hinder zinc deposition during the electrolysis process. The primary objective of the zinc sulphate solution purification process is to obtain an electrolyte solution that is suitable for zinc electrolysis. Since the zinc powder as material is expensive, its consumption should be minimized during the purification process. In previously published literatures, there have been studies related this issue (Fosnachtet et al., 1983; Nyman et al., 1992). Most research has focused on experiments for determining the optimum purification conditions, such as solution temperature, zinc dust particle size, the quantity of zinc dust added, activators concentration and reaction time ( Van Der Pas et al., 1996; Moghaddam et al., 2006).

Previously studies has been interested related this issue and published literatures regarding this topic (Ha M K, et.al., 2001; Li et.al., 2012). The membrane filter press (MFP), which is a common machine on solid-liquid separation, hasadvantages of low cost, high solid content and outstanding efficiency that has been widely used in various industries. The use of a MFP is found to be completely feasible and effective to leach and recover zinc from leaching residues of zinc calcine (Ru et al., 2015). Thereby, improving the technology of zinc production at the stages of solution purification and electrowinning of zinc is relevant. The negative influence of impurities can be reflected both in the decline of the current efficiency - it leads to an increase of the electricity consumption, and in the decrease of the cathode zinc quality due to the increased content of impurities (Sethurajan et al., 2017).

The metal impurities, which are more precious than zinc, can influence the purity of the cathode sediment through co-sedimentation and some of the impurities (cobalt, nickel and copper) facilitate the reverse dissolution of zinc (Muresan et al., 1996) by forming microgalvanic cells with it (Karoleva V., 1986). The harmful effect of these impurities is increased at higher temperatures and acidity of electrolyte, as well as at the simultaneous presence of $\mathrm{Sb}$ and $\mathrm{Ge}, \mathrm{Co}$ and $\mathrm{Cu}$ and other elements in the solution. Table 1 shown in which form are metals present in the original zinc concentrate of Trepca company, respectively their mineralogical composition in $\mathrm{Zn}$ concentrate in percentage .

Table 1. - The mineralogical composition of $\mathrm{Zn}$ concentrate

\begin{tabular}{|l|l|l|l|l|l|l|l|l|l|l|l|}
\hline Minerals & $\begin{array}{l}\text { Total } \\
\%\end{array}$ & $\begin{array}{l}\mathrm{Zn} \\
\%\end{array}$ & $\begin{array}{l}\mathrm{Pb} \\
\%\end{array}$ & $\begin{array}{l}\mathrm{Cu} \\
\%\end{array}$ & $\begin{array}{l}\mathrm{Cd} \\
\%\end{array}$ & $\mathrm{Fe} \%$ & $\begin{array}{l}\mathrm{CaO} \\
\%\end{array}$ & $\begin{array}{l}\mathrm{MgO} \\
\%\end{array}$ & $\mathrm{SiO} \%$ & $\mathrm{~S} \%$ & $\begin{array}{l}\text { Other } \\
\%\end{array}$ \\
\hline $\mathrm{ZnS}$ & 72.14 & 48.44 & & & & & & & & 23.70 & \\
\hline $\mathrm{PbS}$ & 2.56 & & 2.22 & & & & & & & 0.34 & \\
\hline $\mathrm{CuFeS}$ & 1.44 & & & 0.50 & & 0.44 & & & & 0.50 & \\
\hline $\mathrm{CdS}$ & 0.29 & & & & 0.23 & & & & & 0.60 & \\
\hline $\mathrm{FeS} 2$ & 0.67 & & & & & 0.31 & & & & 0.36 & \\
\hline $\mathrm{FeS}$ & 15.99 & & & & & 10.17 & & & & 5.82 & \\
\hline $\mathrm{CaO}$ & 0.46 & & & & & & 0.46 & & & & \\
\hline $\mathrm{MgO}$ & 0.26 & & & & & & & 0.26 & & & \\
\hline $\mathrm{SiO}_{2}$ & 2.12 & & & & & & & & 2.12 & & \\
\hline Other & 4.07 & & & & & & & & & & 4.07 \\
\hline Total & 100.00 & 48.44 & 2.22 & 0.50 & 0.23 & 10.92 & 0.46 & 0.26 & 2.12 & 30.78 & 4.07 \\
\hline
\end{tabular}

\section{BASICS OF PURIFICATION PROCESS OF ZINC SULPHATE SOLUTION}

The purification of zinc sulphate solution from the impurities (metals) is done by separation and cementation and their recovery in metallic forms is overviewed based on the fact that these metals have higher electro-chemical potentials than zinc. The operation factors that have the most profound effect on the process such as impurity concentration, temperature, time, etc. are analyzed, too. The presence of impurities in a zinc electrolyte solution is problematic for the electrowinning process. Impurities act as 
catalysts for hydrogen evolution, which leads to a large drop in current efficiency. Therefore, adequate purification of the zinc electrolyte before electrowinning is essential (Dreher et.al., 2001).

Purification of zinc sulphate solution process shown that this process play important role related the technological, economical and environmental advantages in industry. This process is dependant of numerous process parameters that need to be controlled carefully for future process such is electrolysis of zinc. A proper technique control can make more efficient this process in the industrial practice in all its steps by properly controlling of all process parameters including the quality of solution, adding of reagents, the speed, duration and temperature of the process (Friedrich et.al., 2002).

Depending on the concentration and properties of impurities in the zinc sulphate various chemical and electrochemical refining methods can be used for their recuperation. One of the most known methods is the precipitation or cementation process in which metals of different electrochemical potential are separated by cementation (Kazanbaev et al., 2006). Cementation is the simplest and oldest hydrometallurgical process. It has been used in extractive metallurgy to recover valuable metals as well as to remove unwanted impurities ( Pietrzyk, et al., 2017; Fugleberg, 2014).

Impurities in the zinc sulphate solutions, depending on their concentration and some common properties during the separation process, can be classified into the following groups:

I. $\quad \mathrm{Fe}, \mathrm{Al}, \mathrm{As}, \mathrm{Sb}, \mathrm{Ge}, \mathrm{In}, \mathrm{Ga}, \mathrm{Si}$

II. $\quad \mathrm{Cu}, \mathrm{Cd}, \mathrm{Co}, \mathrm{Ni}, \mathrm{Ta}$

III. $\quad \mathrm{Cl}, \mathrm{Fl}$,

IV. $\quad \mathrm{K}, \mathrm{Na}, \mathrm{Mg}, \mathrm{Mn}$

The zinc sulphate solution is considered to have a high refined degree if it is a very clear solution and has the following characteristics (Purification process, 1982):

solid substances $<0.5 \mathrm{~g} / \mathrm{l}$,

$\mathrm{Fe}^{2+}<5 \mathrm{mg} / \mathrm{l}$,

total $\mathrm{Fe}<15 \mathrm{mg} / \mathrm{l}$,

$\mathrm{Sb}+\mathrm{As}<1 \mathrm{mg} / \mathrm{l}$ and

$\mathrm{pH}=5-5.5$ (Purification process, 1982)

Various methods such as hydrolyse, cementation, catalyst addition etc. can be used to selectively recover the impurities in these groups. These methods have been subject of several research articles and patens (Nelson et al., 2000), but their application in the industrial practice has still difficulties especially in the selection of optimum factors that influence these processes. Trepca company, as per design capacity, can produce about 90,000 t/year zinc sulphate solutions obtained as a by-product of neutral leaching of zinc calcine (Purification Process, 1982). The overall technological flowsheet of zinc production in the Trepca smelter is described in Figure 1. 


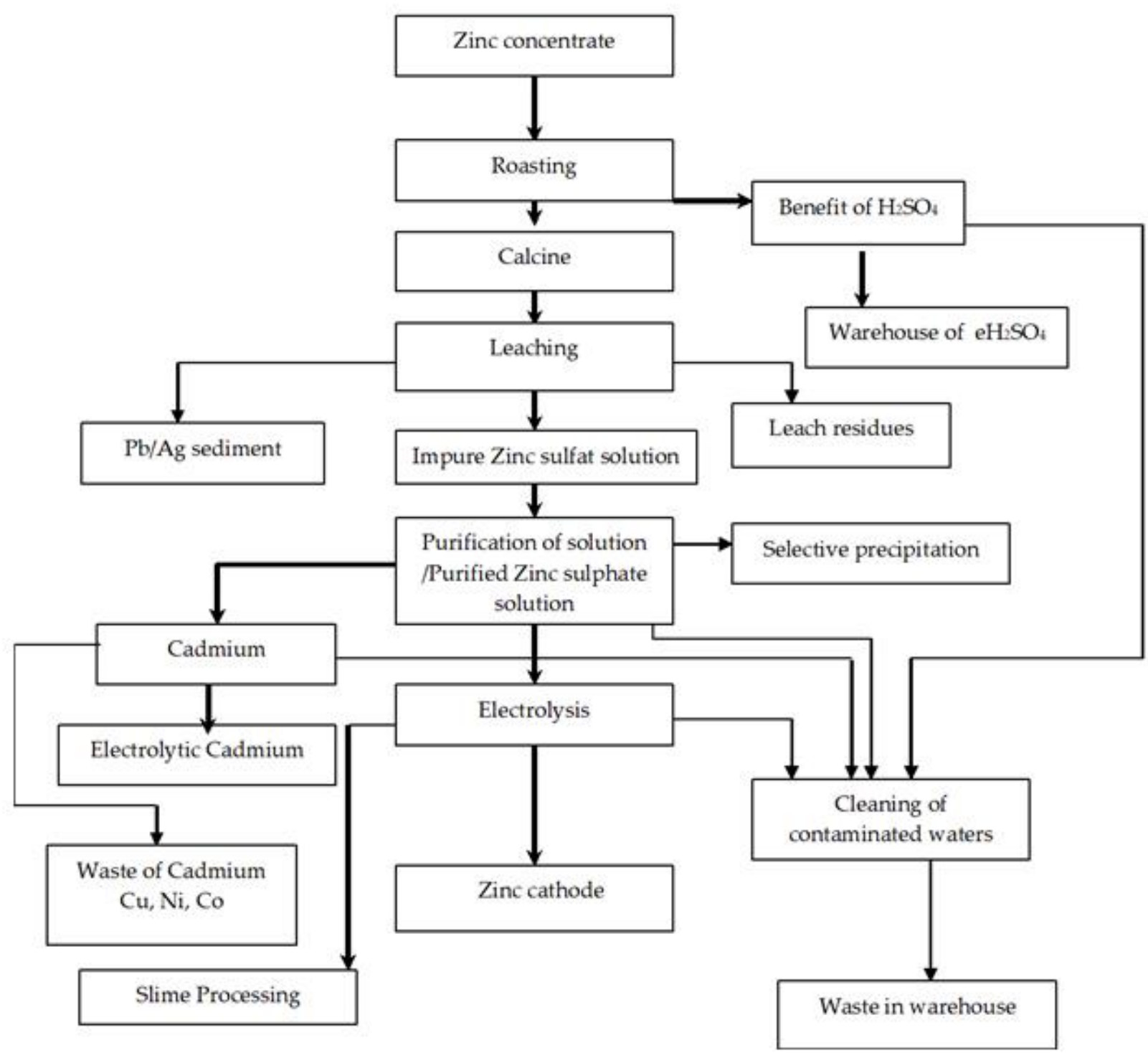

Figure 1. Technological flowsheet for zinc production in the Trepca Smelter

Pyrometallurgical and hydrometallurgical routes or their combination can be employed for treating secondary materials. The hydrometallurgical processes are regarded as more eco-friendly for treating such materials having a low zinc content (Ha M K, et al., 2001).

In the hydrometallurgical process, ores containing zinc are pretreated in hot conditions and then dissolved using sulfuric acids into a zinc sulphate solution. This solution is then purified from various impurity metals such as cobalt, nickel, cadmium, antimony etc., by cementation (Lew, 1994). These metal ions must be removed as they would disturb the following electrolysis of zinc. Cobalt and related metals such as nickel cause damage to the cathode used in the electrolysis process as well as contributing to redissolution of zinc (Boyanov et al., 2004).

In the hydrometallurgical zinc production process, metallic zinc is produced by reducing it from aqueous solution. The essential part of the process is the purification of zinc sulphate solution, where all elements nobler than zinc are removed by deposition from the solution. Controller performance is highly dependent on the reliability of information which is received from measuring devices and from reference measurements. Measured process data is inherently inaccurate and these measurement errors can be caused by random noise, deteriorating, malfunctioning or wrongly calibrated instruments.The correlation analysis used here applies conversely in process control. The results have been exploited in 
the process control of solution purification. In the case of the cobalt removal process, it was necessary to get the continuous solution purification process working reliably and with a high enough deposition efficiency ( Näsi , 2007). As zinc consumption is gradually increasing all the time in the world, many zinc plants are looking for possible expansions. Their preliminary profitability calculations can show that a possible total expansion is not economical, when they are looking to expand the whole roasting/acid plant - leaching - solution purification - electrowinning - casting route, as the possible market price for the sulphuric acid is low or the sulphuric acid market is too far away. Based on these facts, their economical study often indicates that implementing a zinc concentrate direct leaching option could be more favourable ( Svens, 2012).

Due to the relatively low concentration limits, the preparatory purification is of great importance (Han et al., 2016). Cementation is widely used in hydrometallurgical zinc refining to purify zinc sulphate solutions from impurities. The purification is achieved through electrochemical reactions causing the impurity metals to precipitate on the surface of zinc dust. These reactions are commonly known as cementation reactions. A cementation reaction can be described as electrochemical precipitation where the most noble metal ions in a solution are reduced to solid metal through deposition on the surface of a less noble metal which is oxidized (Sethurajan et al., 2017). In the case of zinc purification, the impurity metals are the nobler metals that are to be reduced while zinc, often in the form of zinc dust, is the less noble metal providing the electrons (Lew, 1994; Free, 2013).

There are many companies over the world that employed more less similar methods or some other variations within the purification process of zinc sulphate solution obtained from neutral leaching process of zinc calcine.

\section{PURIFICATION PHASES OF SULPHATE SOLUTION OBTAINED FROM THE LEACHING PROCESS OF ZINC CALCINE}

Based on the analysis presented in the technical documentation of smelter we have these average concentrations of impurities in sulphate solution obtained during the leaching process are given in Table 2.

Table 2. Concentrations of impurities in sulphate solution

\begin{tabular}{|l|l|}
\hline Elements & Concentration $(\mathrm{mg} / \mathrm{l})$ \\
\hline $\mathrm{Cu}$ & $0.2-1.2$ \\
\hline $\mathrm{Cd}$ & $0.2-1.2$ \\
\hline $\mathrm{Co}$ & $1.0-10$ \\
\hline $\mathrm{Ni}$ & $20-50$ \\
\hline $\mathrm{As}$ & $0.1-0.5$ \\
\hline $\mathrm{Ge}$ & $0.1-0.5$ \\
\hline $\mathrm{Sb}$ & $0.1-0.5$ \\
\hline $\mathrm{Se}$ & $0.1-0.5$ \\
\hline $\mathrm{Te}$ & $0.1-0.5$ \\
\hline $\mathrm{Ag}$ & $0.1-0.5$ \\
\hline
\end{tabular}

The purpose of the purification of the sulphate solution obtained from leaching process of zinc calcine, which is the subject of this study, is the process with aim to release the sulphate solutions from impurities and produce a highly refined solution in order that the subsequent process of electrolysis, achieves the best possible quality of zinc and make an efficient use of electricity. The zinc sulphate solution is considered to have a high refined degree if it is a very clear solution and has the following characteristics: solid substances $<0.5 \mathrm{~g} / \mathrm{l}, \mathrm{Fe}^{2+}<5 \mathrm{mg} / \mathrm{l}$, total $\mathrm{Fe}<15 \mathrm{mg} / \mathrm{l}, \mathrm{Sb}+\mathrm{As}<1 \mathrm{mg} / \mathrm{l}$ and $\mathrm{pH}=5-5.5$. 
Refining of the zinc sulphate in Trepca smelter is carried out in two phases: cold and hot. The refined solution is subsequently mixed with acid, cooled and sent for electrolysis. The residues of the process are treated to increase the recovery coefficient of cadmium and zinc .

\section{Cold Refining}

The cold refining is the first phase of the purification process, that enable selective multi-tank sedimentation of impurities such as $\mathrm{Cu}, \mathrm{Cd}, \mathrm{Tl}$ and part of $\mathrm{Ni}$ (approximately $12 \mathrm{mg} / \mathrm{l}$ ). This is carried out through the added zinc powder. The amount of zinc powder needed for the process, is calculated according to the following equation:

$$
Z n(g / l)=0.5(g / l)+1.2 C u(g / l)+1.5 C d(g / l)
$$

The zinc powder is used not only in the first tank but also and in the second tank, in order to precipitate any $\mathrm{Cd}$ amount which may have accidentally penetrated. Generally, in the cold refining stage the precipitation of $\mathrm{Cu}$ and $95 \%$ of $\mathrm{Cd}$ is achieved as well as part of $\mathrm{As}, \mathrm{Sb}, \mathrm{Tl}, \mathrm{Ge}$ and Ni. Duration time of reaction is an important factor in this phase and normally is about 45 mins but longer times especially longer than an hour and a half can cause oxidization of $\mathrm{Cd}$ which can pass again in the solution. To increase the speed of filtration the solution needs to be heated in the last tank. Precipitation of the Co and especially of $\mathrm{Ni}$, is done successfully by adding of $\mathrm{As}$ and $\mathrm{Sb}$. However if the content of As and $\mathrm{Sb}$ in the neutral solution is high- an indication that $\mathrm{As}$ and $\mathrm{Sb}$ were not removed at the right degree during neutral leaching - $\mathrm{Co}$ and $\mathrm{Ni}$ can partly precipitate thus increasing the undesirable quantities of $\mathrm{Co}$ and $\mathrm{Ni}$ in $\mathrm{CdSO}_{4}$ solution. The filtrate is sent to hot refining stage and the sedimentation is sent for further processing of $\mathrm{Cu}$ and $\mathrm{Cd}$ (Purification Process, 1982).

\section{Hot Refining}

Elements which have not precipitated in the first phase such as $\mathrm{Ni}, \mathrm{Co}, \mathrm{Sb}, \mathrm{Ge}$ as well and other impurities can be removed during this second phase. This is done by adding zinc powder and antimony oxide $\left(\mathrm{Sb}_{2} \mathrm{O}_{3}\right)$ and increasing the temperature up to $90{ }^{\circ} \mathrm{C}$. The amount of zinc powder needed for process is calculated according to the following equation:

$$
Z n(g / l)=1(g / l)+100 C o(g / l)+50 N i(g / l)
$$

Zinc powder particles must be smaller than $75 \mu \mathrm{m}$, in order to speed up their solubility and to avoid using excessive amount of zinc powder.

$\mathrm{Sb}_{2} \mathrm{O}_{3}$ is used as addition because along with the added zinc metal powder it creates a catalyst that accelerates the solubility of zinc and the precipitation of $\mathrm{Co}$ and Ni. However, the amount of $\mathrm{Sb}_{2} \mathrm{O}_{3}$ added to the solution should be limited because a larger than necessary amount causes reversed dissolution of Co precipitate. Furthermore the excess of $\mathrm{Sb}$ does not fully precipitate and this has an impact on the process of electrolysis.

In this stage $\mathrm{Pb}$ is also added into the solution in the form of oxide or sulphate in order to:

- reduce the repetitive tendency of dissolution of Co precipitate,

- reduce the formation of basic zinc sulphate,

- improve the conditions to remove the $\mathrm{Tl}$.

The solution should be kept in the reservoir a few hours, then empties as necessary because if the solution stays for longer periods, impurities such as Co dissolve and Zn gets oxidized which makes the 
filtration process difficult. Normally the duration of chemical reaction in this phase is 3 hours and the temperature $90-95{ }^{\circ} \mathrm{C}$. The solution is filtered and the filtrate is checked for quality. The process is considered cleaned if the filtrate contains approximately $0.15 \mathrm{mg} / \mathrm{l} \mathrm{Co}$, and $0.01 \mathrm{mg} / \mathrm{l} \mathrm{Sb}$. After filtration when the temperature is about $80^{\circ} \mathrm{C}, \mathrm{H}_{2} \mathrm{SO}_{4}$ electrolyte is added into the cleaned solution until it reaches a concentration of 2-3 g/l free $\mathrm{H}_{2} \mathrm{SO}_{4}$. This is done in order to avoid the closing of the pipes. The solution is then cooled to near $30^{\circ} \mathrm{C}$ and send to electrolysis. The process continues with re-pulping of $\mathrm{Co}, \mathrm{Ni}, \mathrm{Cu}$ and $\mathrm{Cd}$, in order to increase the yield of $\mathrm{Zn}$. Filtering residues are then sent for processing of $\mathrm{Co} / \mathrm{Ni}$ (Purification Process, 1982).

The process of refining of sulphate solutions and recovering of valuable materials from it is a complex process whose normal running and its efficiency depends on numerous process parameters. These parameters in the Trepca process include the content of solid substances, $\mathrm{Fe}^{2+}, \mathrm{Fe}$ total and $\mathrm{Sb}+\mathrm{As}$ concentration of $\mathrm{pH}$ of solution, added amount and the size of particles of zinc powder during cold and hot refining, processing time and temperature, the speed of filtration, lead quantity, mixing with the electrolyte.

\section{CONCLUSION}

Purification of zinc sulphate solution process shown that this process play important role related the technological, economical and environmental advantages in industry. This process is dependant of numerous process parameters that need to be controlled carefully for future process such is electrolysis of zinc. A proper technique control can make more efficient this process in the industrial practice in all its steps by properly controlling of all process parameters including the quality of solution, adding of reagents, the speed, duration and temperature of the process. This purification way the of sulphate solution can maximize the economic benefits by efficiently separating of valuable metals that are present in the solution including $\mathrm{Cu}, \mathrm{Cd}, \mathrm{Co}, \mathrm{Ni}, \mathrm{As}, \mathrm{Ge}, \mathrm{Sb}$, Se and Te. Based on the above data, it is evident that the selective recovery of these metals from these solutions represents a significant economic added value , and from the environmental point of view this eliminates the need of unnecessary and sometimes risky land filling with valuable metals. In this point of view, in order to revive and improve operation practices as per design capacity in the Trepca Company, a new project needs to be undertaken, in order to increase efficiency of the process through proper control and optimization. The drawbacks of the conventional zinc solution purification process are an economical and technical incentive to search for ways to improve the performance of the purification systems.

\section{REFERENCES}

Boyanov, S.B., Victoria, V.K., Nikolai, K.K., 2004, "Purification of zinc sulfate solutions from cobalt and nickel through activated cementation", Hydrometallurgy 73, 163-168.

Dreher T.M., Nelson A., Demopoulos G.P., Filippou D., 2001, "The Kinetics of Cobalt Removal by Cementation from an Industrial Zinc Electrolyte in the Presence of $\mathrm{Cu}, \mathrm{Cd}, \mathrm{Pb}, \mathrm{Sb}$ and $\mathrm{Sn}$ Additives" Hydrometallurgy, 60, pp. 105-116,

Friedrich Berndt., Kruger Joachim, Mendez Bernal Graciella ,2002 “ Alternative solution purification in the hydrometallurgical zinc production", Savez Inzenjera metalurgije Jugoslavije

Free M, lebrary (e-book collection).2013 Hydrometallurgy: fundamentals and applications. Hoboken, N.J: TMS-Wiley;

Fosnachtet, D. R., O'Keefe T. J., 1983, “The effects of certain impurities and their interactions on zinc electrowinning", Metallurgy Transactions, 14, 645-655

Fugleberg S., 2014, "Improving the competitiveness of the electrolytic zinc process by chemical reaction engineering approach" Laboratory of Industrial Chemistry and Reaction Engineering,

Ha M K, et.al., Kumar V, Singh R J,2001 “ Review of hydrometallurgical recovery of zinc from industrial wastes ", Resources Conservation and Recycling, 2001, 33(1): 1-22 
Han J., Liu W., Qin W., Zheng Y., and Luo H., 2016, “Optimization Study on the Leaching of High IronBearing Zinc Calcine After Reduction Roasting," Metallurgical andMaterials Transactions B: Process Metallurgy and Materials Processing Science, vol. 47, no. 1, pp. 686-693,

Karoleva V., “Metallurgy of non-ferrous metals”, V.2, Technika, Sofia, 1986 (in Bulgarian)

Kazanbaev L.A., Kozlov P.A., Kubasov V.L., Kolesnikov A.V., 2006 “Zinc Hydrometallurgy", Ore and Metals, p. 176

Lew R. W.,1994. "The removal of cobalt from zinc sulphate electrolytes using copper-antimony process" Vol. British columbia, Vancouver, Canada,

Li Mi, Peng Bing, Chai Li-yuan, Peng Ning, Yan Huan, Hou Dong-ke, 2012 “ Recovery of iron from zinc leaching residue by selective reduction roasting with carbon ", Journal of Hazardous Materials, 2012, 237-238: 323-330

Moghaddam J., Sarraf-Mamoory R., Abdollahy M., Yamini Y.,2006 “Purification of zinc ammoniacal leaching solution by cementation: Determination of optimum process conditions with experimental design by Taguchi's method", Separation and Purification Technology, 51, 157-164

Muresan L., Maurin G., Oniciu L. and Gaga D., Hydrometallurgy, 43 (1996) 345.

Näsi J., 2007 “ Intensified use of process measurements in hydrometallurgical zinc production processes" Faculty of Technology of the University of Oulu

Nelson A., Demopoulos G.P. and Houlachi G., 2000 "The effect of solution constituents and novel activators on cobalt cementation", Canadian Metallurgical Quarterly, Vol 39, No 2, pp. 175186.Process Chemistry Centre .Department of Chemical Engineering, Åbo Akademi University Turku/Åbo Finland

Nyman B., Aaltonen A., Hultholm S. E., K. Karpale,1992 “ Application of new hydrometallurgical develop-ments in the Outokumpu HIKO process", Hydrometallurgy, 29(1992), 461-478

Pietrzyk S., Palimąka P., Stępień M., Krawczykowska A., Tora B., Fatyga M., Pajor G., and Mańka A., 2017 "Silver recovery from zinc metallurgical sludge - analysis of solutions" E3S Web of Conferences 18,01027 MEC2017

Purification Process, Vieille Montagne, 1982 Operating Guide, Book III, Trepca mine, zinc plant, 1982, Mitrovica, Kosovo

Ru, Zhen-guang, Pan Cen-xuan, Liu Gui-hua, Wang Xue-ting, Dou Guang-yu, Zhu Ke-song, 2015 "Leaching and recovery of zinc from " Leaching residue of zinc calcine based on membrane filter press" Trans. Nonferrous Met. Soc. China 25, 622-627

Sethurajan M., Huguenot D., R. Jain et al., 2017“Leaching and selective zinc recovery from acidic leachates of zinc metallurgical leach residues", Journal of Hazardous Materials, vol. 324, pp. 7182 ,

Svens K.,2012 "Direct leaching alternatives for zinc concentrates",T.T. Chen Honorary Symposium on Hydrometallurgy, Electrometallurgy and Materials Characterization, TMS (The Minerals, Metals \& Materials Society)

Turan M. Deniz, Altundogan H. Soner, Tumen Fikret, 2004 “Recovery of zinc and lead from zinc plant residue", Hydrometallurgy 75 (2004) 169-176,

Van Der Pas V., Dreisinger D. B., 1996 "A fundamental study of cobalt cementation by zinc dust in the presence of copper and antimony additives", Hydrometallurgy, 43, 187-205 